\title{
Age Induced Gamma Prime Coarsening and Hardness Behavior in Pyromet 31V
}

\author{
N.D. Evans, ${ }^{*}$ Y. Yamamoto, * P.J. Maziasz, ${ }^{*}$ and J.P. Shingledecker* \\ *Metals and Ceramics Division, Oak Ridge National Laboratory, Oak Ridge, TN 37831-6376
}

Significant increases in efficiencies of natural gas powered reciprocating engine systems (ARES) will likely require increases in engine operating temperatures and pressures. This in turn will place increased demands on the engine's high temperature exhaust components such as valves, seats, exhaust manifold, and turbocharger housing. Although an alloy's response to service at time and temperature can be discerned through laboratory study, it is inherently difficult to determine actual temperatures sustained by moving engine components during service. Consequently in these engine systems, service time is known, but the local operating temperature within components is uncertain. Pyrometry provides some measure of temperature, but is limited to measurements of only some surfaces of some components. Computational modeling is used to predict operating temperatures, thermal gradients, and stresses, but it must still be validated from measurements.

In this study, the temperature-dependent coarsening rate of $\gamma^{\prime}$ precipitates was characterized in Pyromet 31V (Ni-22Cr-15Fe, with $\mathrm{Ti}$ and $\mathrm{Al}$ additions for $\gamma^{\prime}$ dispersion strengthening). This superalloy is presently used in the tulip region of some ARES exhaust valves. Alloy samples were heat treated in argon-filled quartz ampoules for $100 \mathrm{~h}, 1000 \mathrm{~h}$, and $3000 \mathrm{~h}$ at 700,750 , and $800^{\circ} \mathrm{C}$. Prior to annealing, specimens were either solutionized $\left(4 \mathrm{~h}\right.$ at $1093^{\circ} \mathrm{C}$, oil quench; designated "SA") or solutionized and heat treated $\left(4 \mathrm{~h}\right.$ at $1093^{\circ} \mathrm{C}$, oil quench; $4 \mathrm{~h}$ at $857^{\circ} \mathrm{C}$, air cool; $4 \mathrm{~h}$ at $732^{\circ} \mathrm{C}$, air cool; designated "SA+HT"). The SA+HT specimens, having multiple heat treatments, represented the actual heat treatment schedule of valves prior to service, whereas the SA specimens were expected to yield a better precipitate size distribution.

From the SA and SA+HT samples, TEM specimens were made using conventional grinding and electropolishing techniques. Images of $\gamma^{\prime}$ precipitates were acquired in either bright field (Fig. 1a) or centered dark field $\left(\{001\}_{\gamma^{\prime}}\right)$ modes. Precipitate boundaries, where the boundary could be noted with confidence, were manually masked in Photoshop (version 8) to produce corresponding binary images (Fig. 1b). Diameters of $\gamma^{\prime}$ precipitates were measured from the binary images using ImagePro Plus (version 4.5). These values were used to determine the temperature-dependent rates of $\gamma^{\prime}$-volume change (Fig2a). These rates were used to calculate an activation energy for volume diffusion developed by Lifshitz and Slyozov and by Wagner (the LSW theory) [1,2]. With this activation energy and service time known, the local operating temperature for components made from Pyromet $31 \mathrm{~V}$ can now be estimated from measurement of $\gamma^{\prime}$ precipitate diameters. Additionally, Vickers Hardness measurements of SA and SA+HT samples were acquired, and provide useful insights into this alloy's response to aging (Fig. 3).

The applicability and limitations of applying LSW theory to this multicomponent system, which has a large volume fraction of precipitates and undergoes multiple heat treatments, will be discussed [3].

\section{References}

[1] I. M. Lifshitz and V.V. Slyozov, J. Phys. Chem. Solids, 19 (1961) 35.

[2] C. Wagner, Z. Electrochem., 65 (1961) 581.

[3] Research sponsored by the Office of Distributed Energy and Electricity Reliability under the Assistant Secretary for Energy Efficiency and Renewable Energy, and at the Oak Ridge National Laboratory SHaRE User Facility by the Office of Basic Energy Sciences, U.S. Department of Energy, under contract DE-AC05-00OR22725 with UT-Battelle, LLC.

Discussions with G. Muralidharan, ORNL, are gratefully acknowledged. 

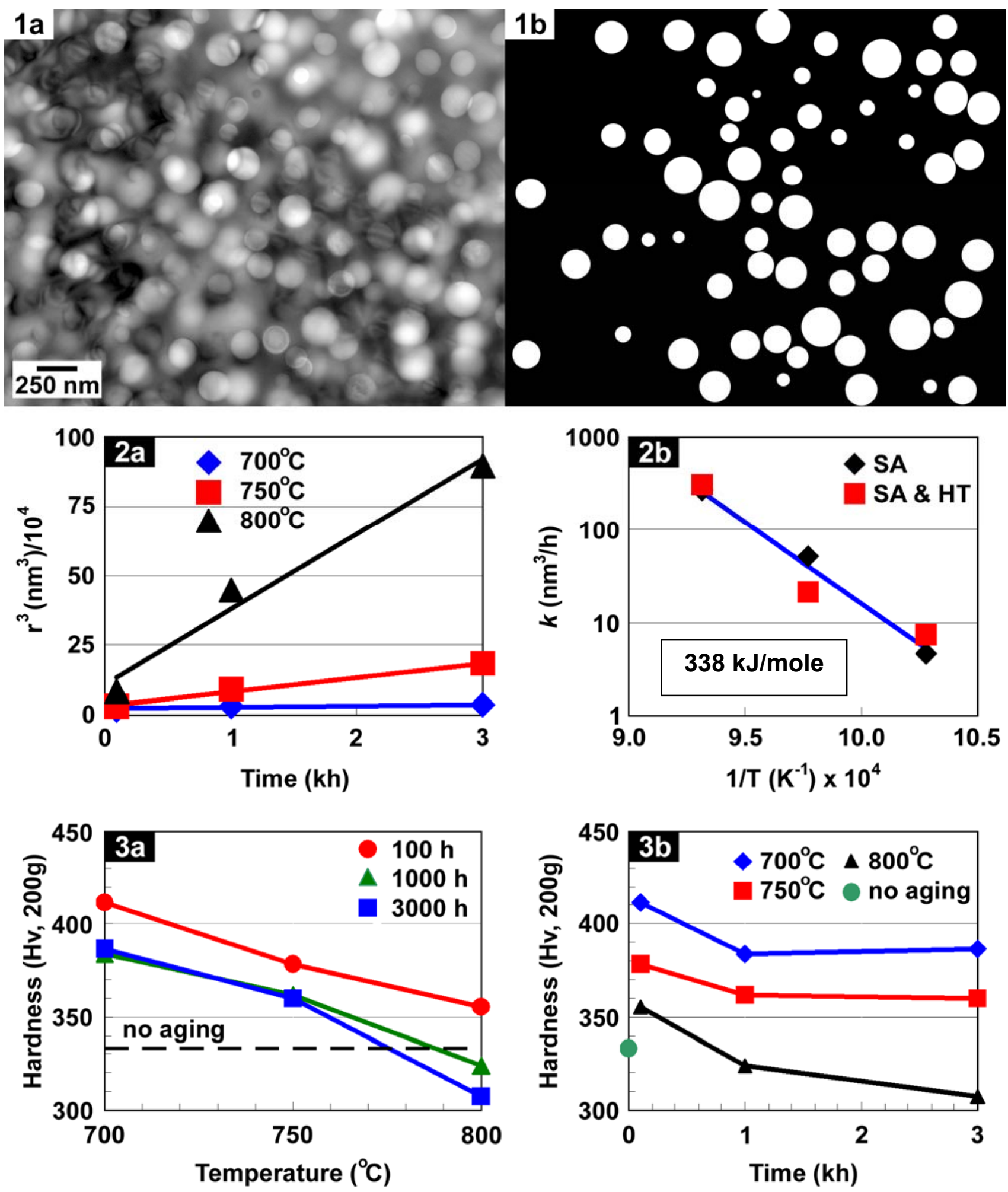

FIG 1. $\alpha.) \gamma^{\prime}$ precipitates in aged Pyromet $31 \mathrm{~V}$; b.) binary image constructed from image in a.) FIG 2. a.) Temperature-dependent growth rates of $\gamma^{\prime}$ precipitates; b.) Activation energy for diffusion FIG 3. Hardness behavior of aged Pyromet $31 \mathrm{~V}$ in SA+HT condition: a.) Temperature; and b.) time dependent hardness 